Supporting Information

\title{
Exploring the Interfacial Chemistry between Zinc Anodes and Aqueous Electrolytes via an In Situ Visualized Characterization System
}

Xunzhu Zhou, Yong Lu, Qiu Zhang, Licheng Miao, Kai Zhang, Zhenhua Yan, Fujun Li*, and Jun Chen*

Key Laboratory of Advanced Energy Materials Chemistry (Ministry of Education), Renewable Energy Conversion and Storage Centre (RECAST), College of Chemistry, Nankai University, Tianjin, P. R. China

E-mail: fujunli@nankai.edu.cn; chenabc@nankai.edu.cn 
a

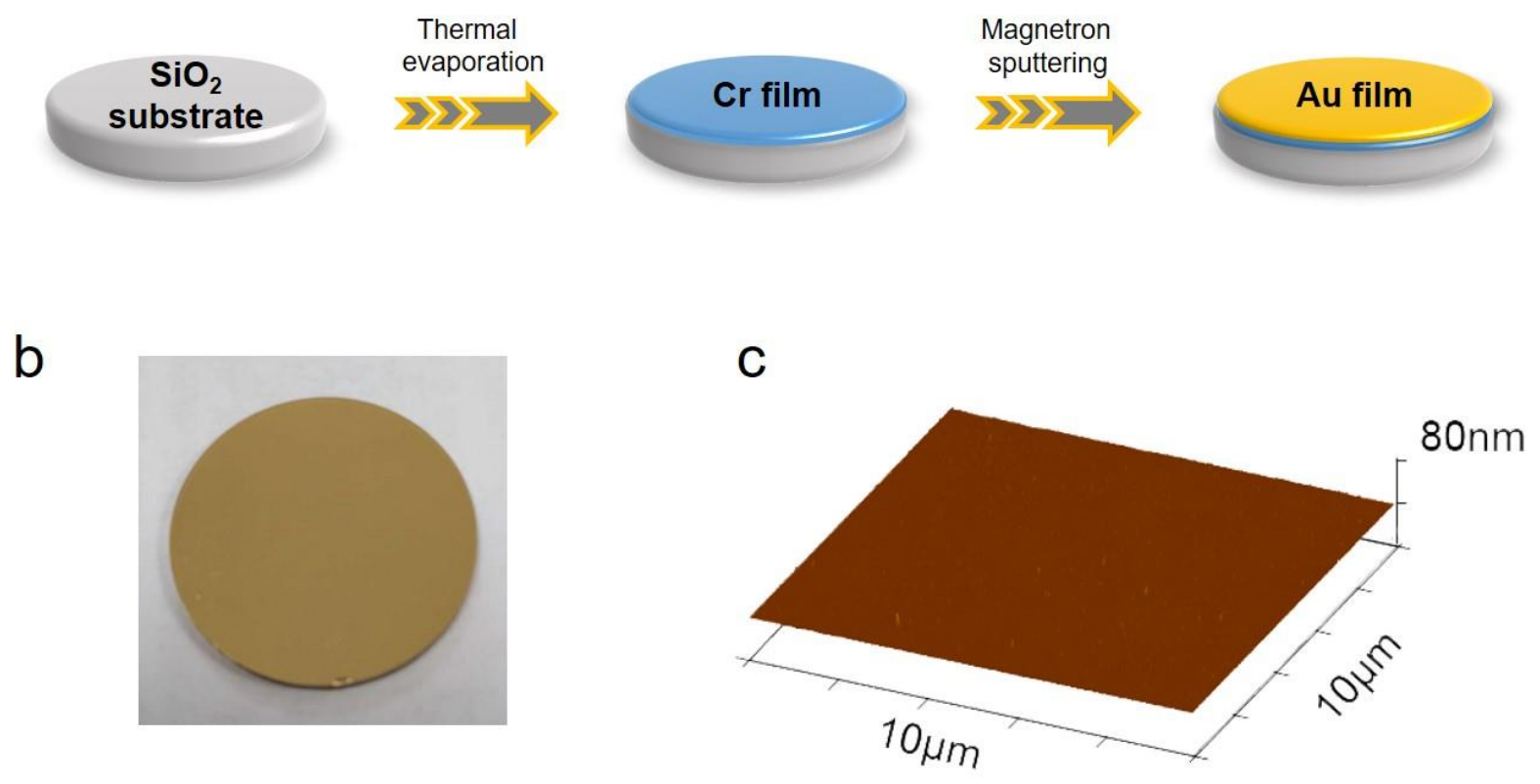

Figure S1. (a) Preparation process, (b) photograph and (c) 3D AFM height image of the homemade planar electrode. 


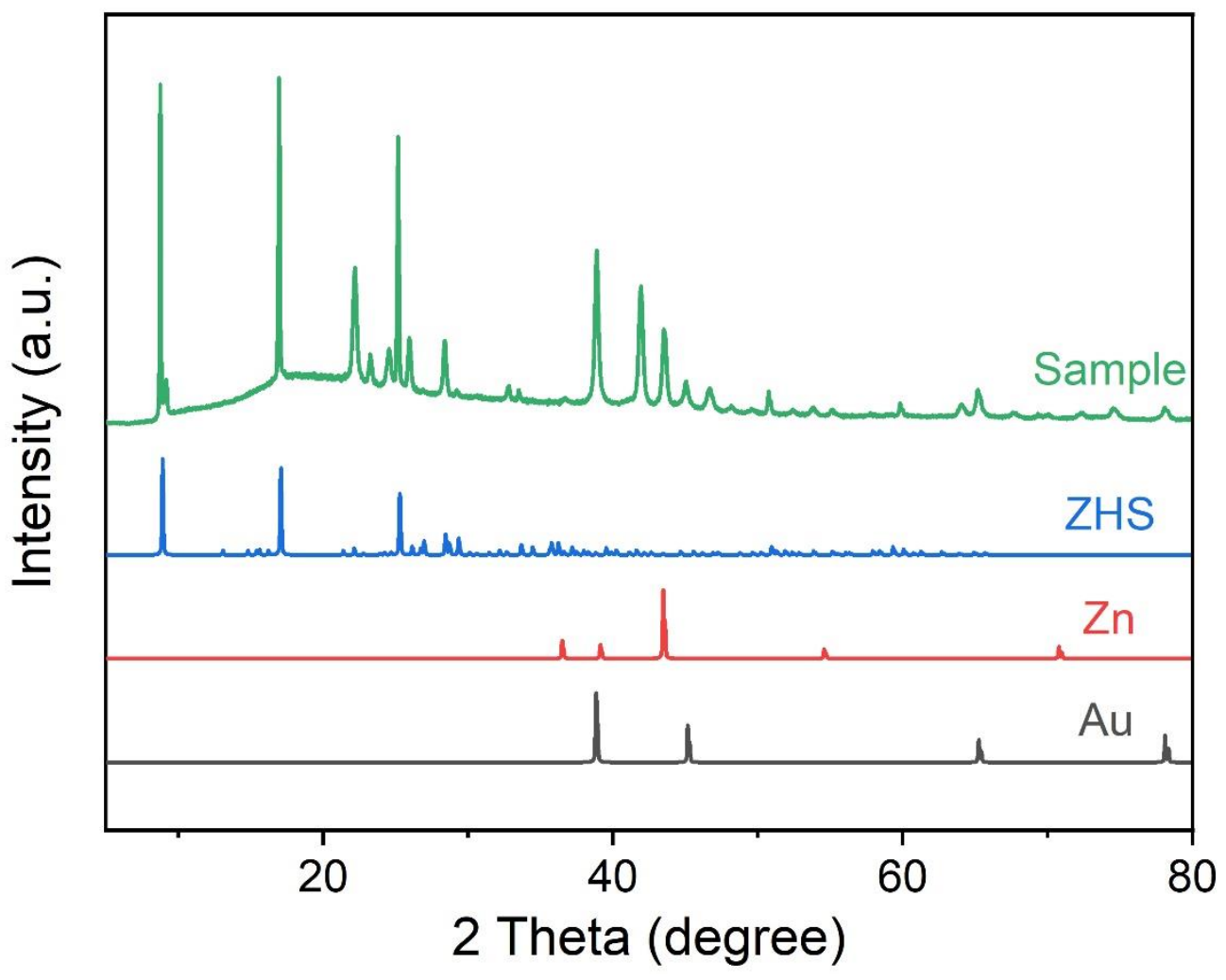

Figure S2. XRD pattern of home-made electrode after depostion. 

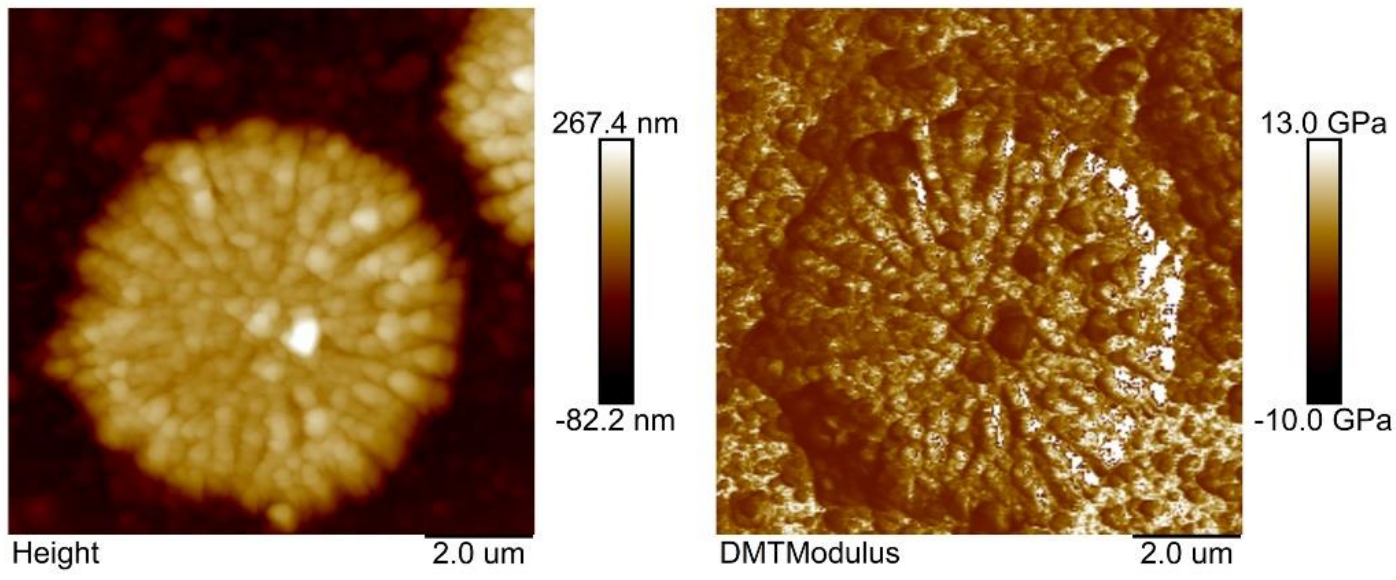

Figure S3. AFM height image (left) and corrsponding Young's Modulous image (right) of deposited $\mathrm{Zn}$. 

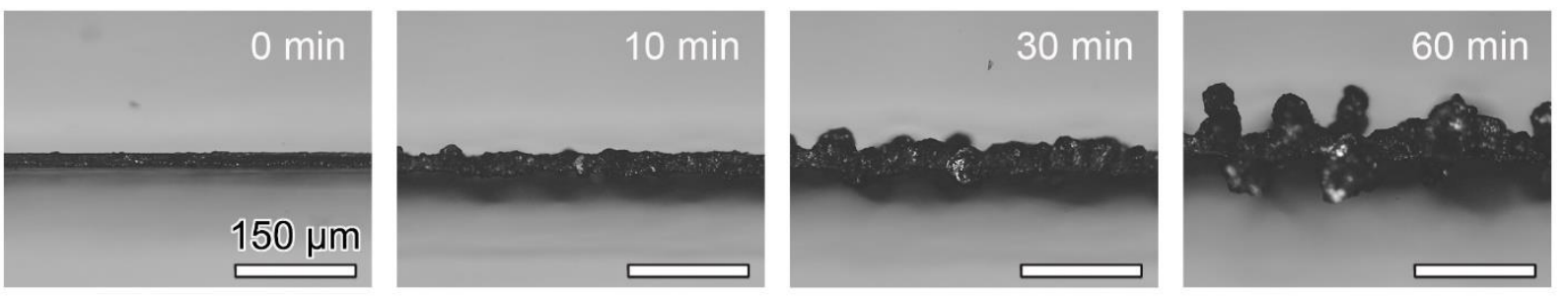

Figure S4. Optical cross-section observations of the $\mathrm{Zn}$ deposition morphologies as a function of deposition time in $1.0 \mathrm{M} \mathrm{ZnSO}_{4}$ electrolyte. The current density is $40 \mathrm{~mA} \mathrm{~cm}$. 


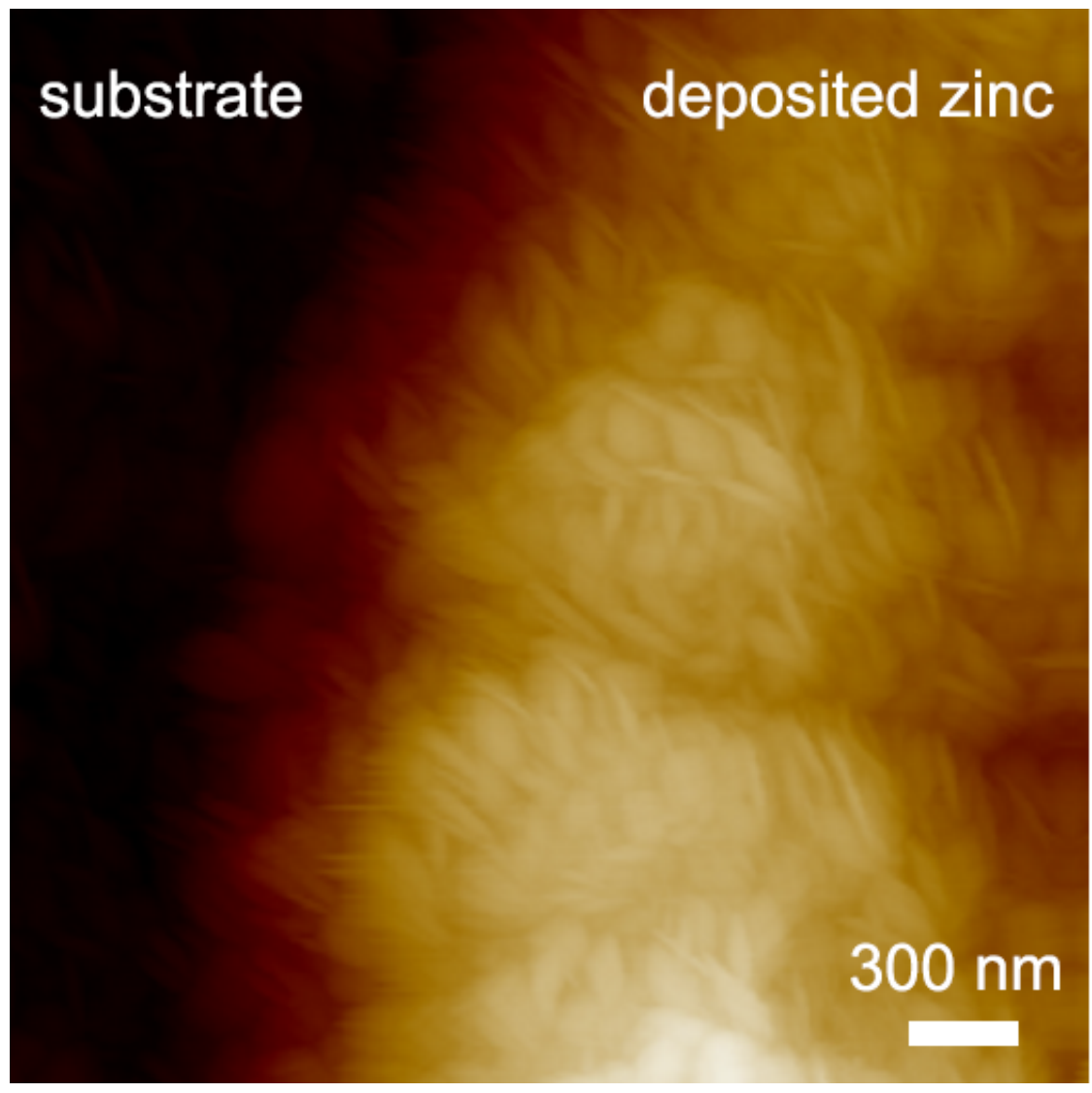

Figure S5. Enlarged AFM image of deposited Zn. The date sacle is $300 \mathrm{~nm}$. 


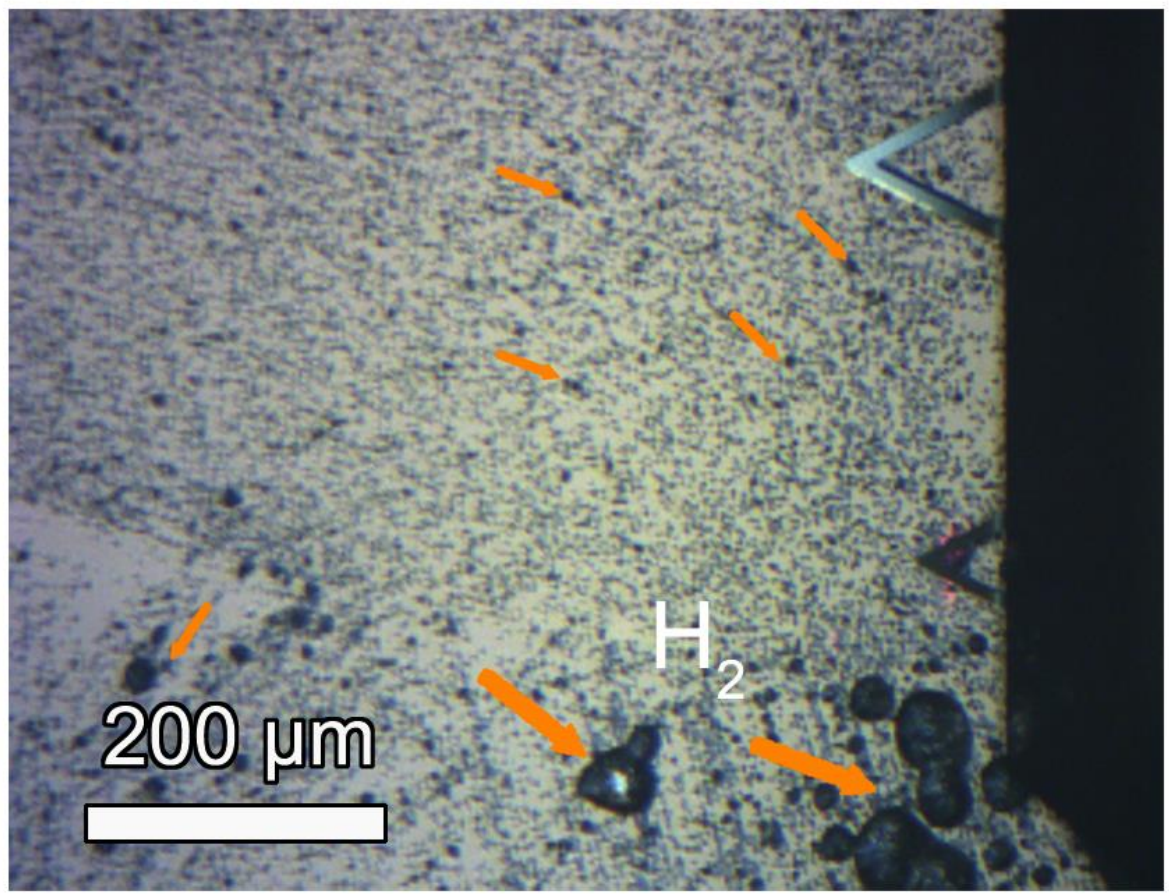

Figure S6. Image captured by optical camera equipped on AFM. 

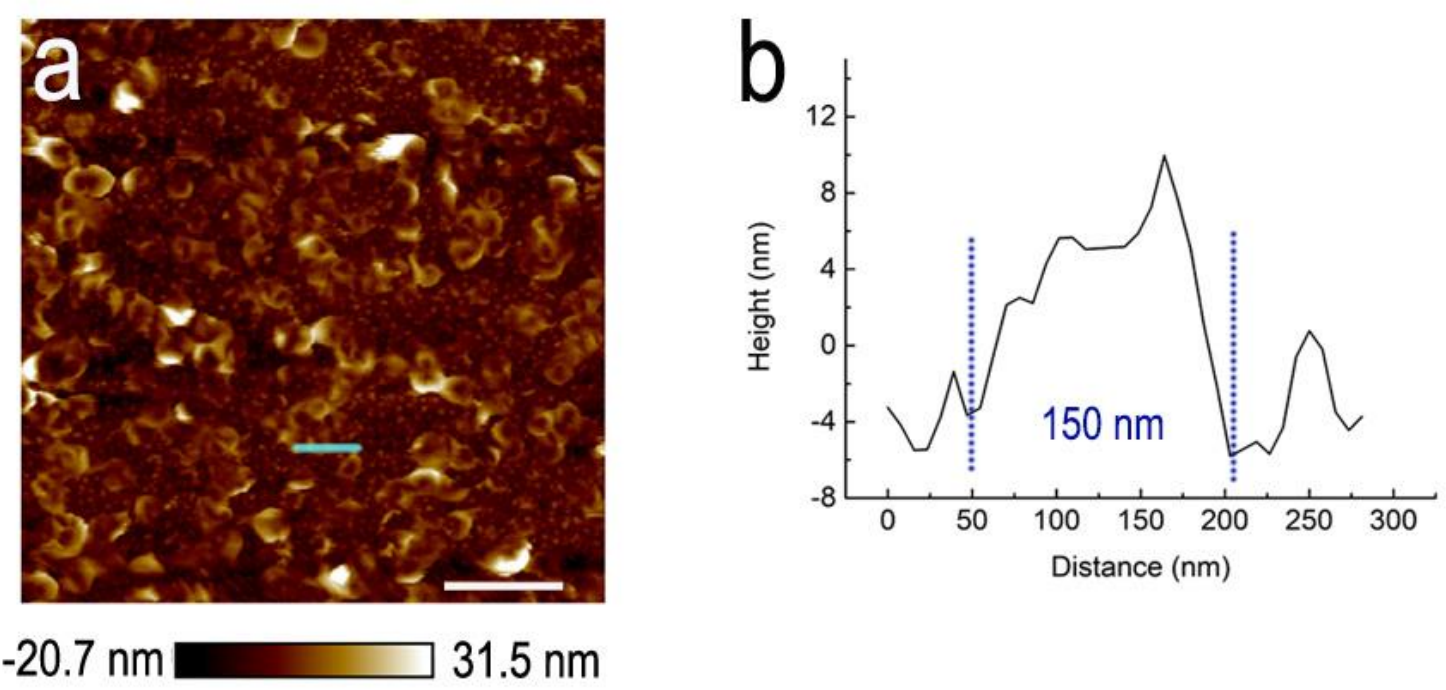

Figure S7. (a) Morphology and (b) corresponding height of $\mathrm{Zn}_{4}(\mathrm{OH})_{6} \mathrm{SO}_{4} \cdot 5 \mathrm{H}_{2} \mathrm{O}$. The scale bar is $600 \mathrm{~nm}$. 


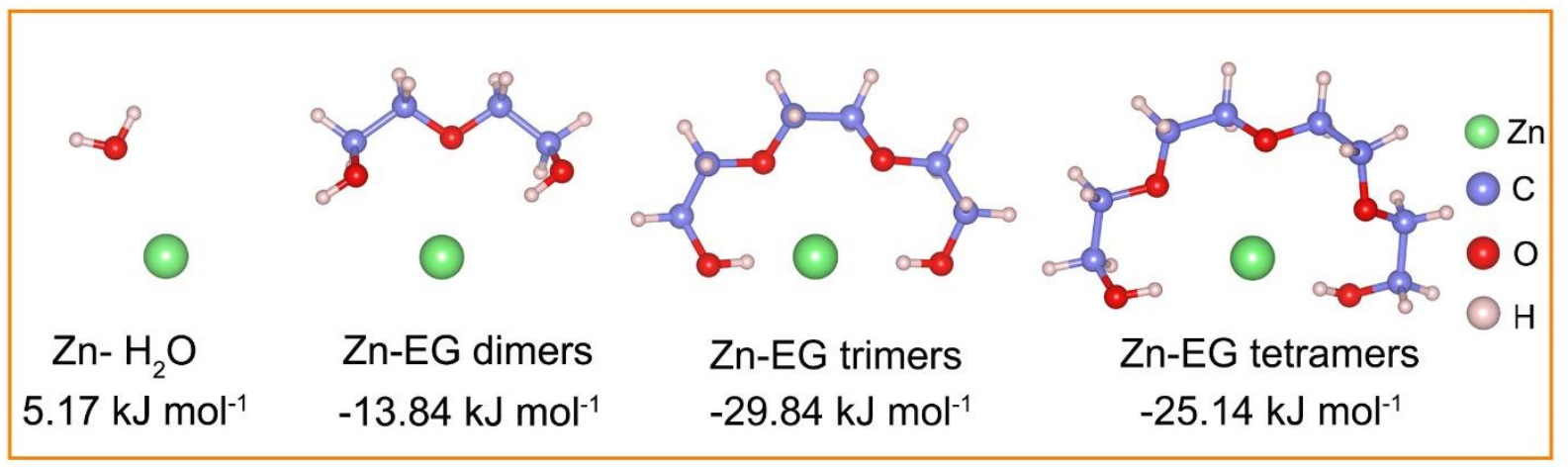

Figure S8. Configurations and bonding energies of $\mathrm{Zn}-\mathrm{H}_{2} \mathrm{O}$, Zn-EG dimers, $\mathrm{Zn}-\mathrm{EG}$ trimers and $\mathrm{Zn}$-EG tetramers. The theoretical calculation was applied to explain the function of PEG for inhibiting hydrogen evolution. In consideration of tremendous molecular weight of PEG, we chose several EG oligomers as the study objects and found their tendency to predict the Zn-PEG interaction. The bonding energy (BE) of $\mathrm{Zn}-\mathrm{H}_{2} \mathrm{O}$ is $5.17 \mathrm{~kJ} \mathrm{~mol}^{-1}$, while those of $\mathrm{Zn}-\mathrm{EG}$ oligomers (the polymerization degree $\mathrm{n}$ is from 2 to 4 ) are in the range of $-13.84 \sim-25.14 \mathrm{~kJ}$ $\mathrm{mol}^{-1}$ (attributed to the van der Waals interaction force), which indicates that $\mathrm{Zn}$ prefers to being absorbed by PEG rather than interacting with free water. The PEG additive is able to suppress water-induced parasitic reactions. 

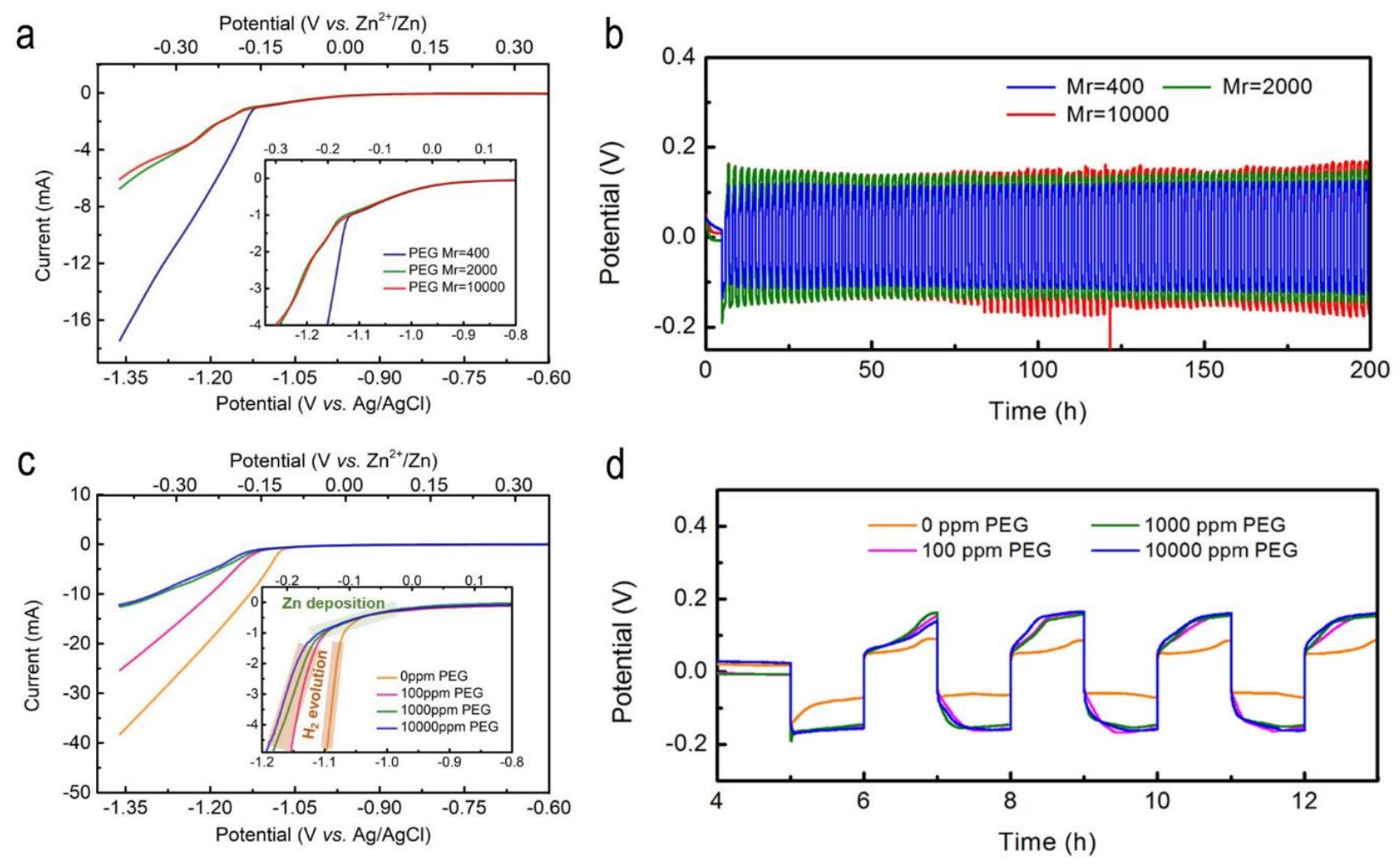

Figure S9. Linear sweep voltammetry (LSV) curves and potential-time curves of $\mathrm{Zn} / / \mathrm{Zn}$ symmetric battery for optimizing the (a-b) weight and (c-d) concentration of PEG additive. The insets are enlarged views. To choose the optimal molecular weight and concentration of PEG, LSV is scanned from -0.60 to $-1.38 \mathrm{~V} \mathrm{vs.} \mathrm{Ag} / \mathrm{AgCl}$ at a sweep rate of $5 \mathrm{mV} \mathrm{s}^{-1}$ in electrolytic cell, with graphite as working electrode, stainless steel as counter electrode, and $\mathrm{Ag} / \mathrm{AgCl}$ as reference electrode. When the molecular weight of PEG is increased from 400 to $2000 \mathrm{~g} \mathrm{~mol}^{-1}$, the overpotential of hydrogen evolution reaction (HER) is obviously reduced. But the HER overpotential seems unchanged if the molecular weight of PEG is further augmented. The concentration optimization experiment reveals that the high content of PEG lowers the overpotential of hydrogen evolution, but excessive PEG (more than $1000 \mathrm{ppm}$ ) makes no difference because the whole surface has already covered by PEG. Therefore, 1.0 $\mathrm{M} \mathrm{ZnSO}_{4}-1000$ ppm PEG $(\mathrm{Mr}=2000)$ in water is chosen as the optimized electrolyte. 


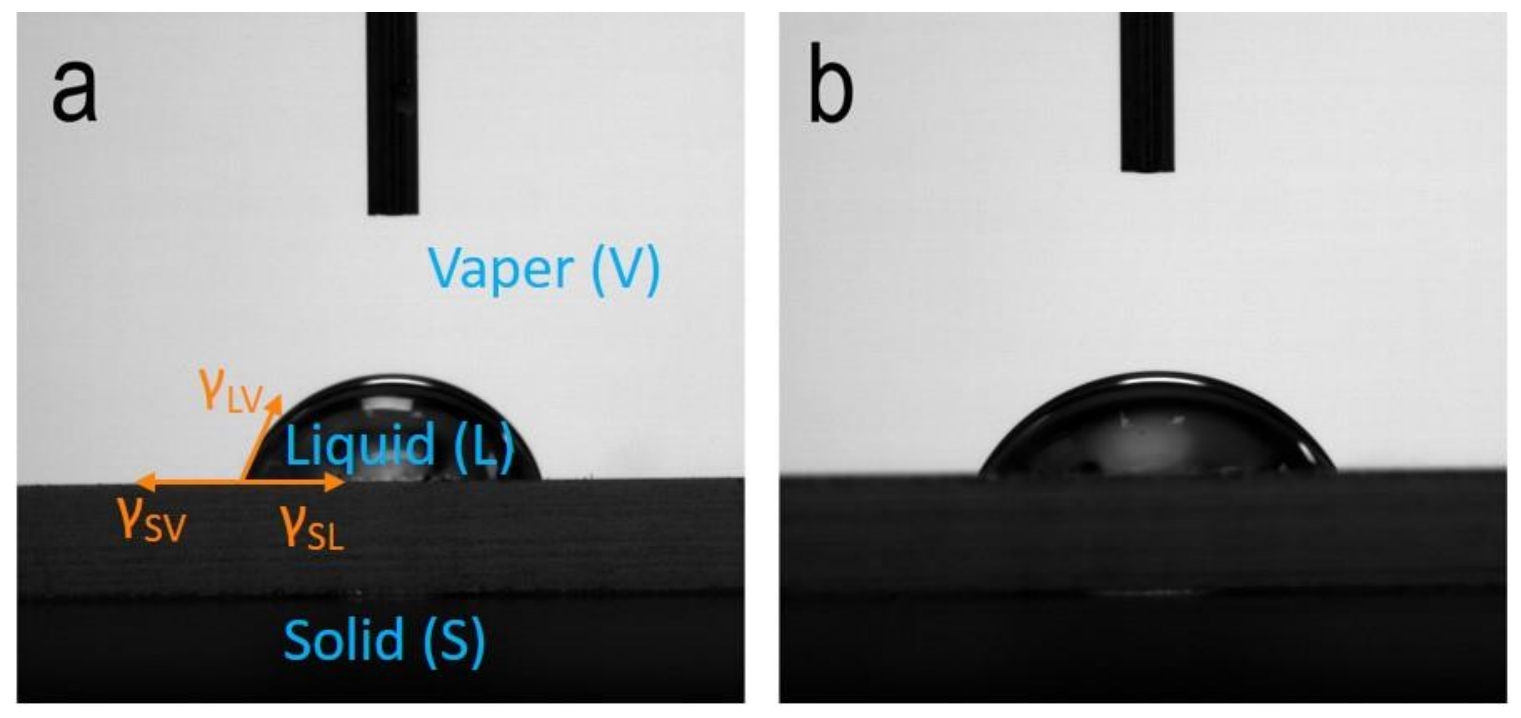

Figure S10. Contact angle of (a) $1.0 \mathrm{M} \mathrm{ZnSO}_{4}\left(72.8^{\circ} / 73.7^{\circ}\right.$ of right/left contact angle) and (b) 1.0 $\mathrm{M} \mathrm{ZnSO}_{4}-1000$ ppm PEG electrolyte $\left(60.6^{\circ} / 59.6^{\circ}\right.$ of right/left contact angle) with $\mathrm{Zn}$. 
Table S1. Physical properties of 1.0 $\mathrm{M} \mathrm{ZnSO}_{4}$ and 1.0 $\mathrm{M} \mathrm{ZnSO}_{4}-1000$ ppm PEG electrolyte.

\begin{tabular}{cccccc}
\hline Electrolyte & $\begin{array}{c}\text { Ionic conductivity } \\
/ \mathrm{mS} \mathrm{cm}^{-1}\end{array}$ & $\begin{array}{c}\text { Viscosity } \\
/ \mathrm{mPa} \mathrm{s}\end{array}$ & $\mathrm{pH}$ & $\begin{array}{c}\text { Contact angle } \\
\text { Right } / \text { Left }\end{array}$ & $\begin{array}{c}\text { Surface tension } \\
\gamma_{L V} / \mathrm{mN} \mathrm{m}^{-1}\end{array}$ \\
\hline $1.0 \mathrm{M} \mathrm{ZnSO}_{4}$ & 49.7 & 2.392 & 4.01 & $72.8^{\circ} / 73.7^{\circ}$ & 70.26 \\
$1.0 \mathrm{M} \mathrm{ZnSO}_{4-}$ & 31.9 & 2.218 & 3.98 & $60.6^{\circ} / 59.6^{\circ}$ & 59.31 \\
$1000 \mathrm{ppm} \mathrm{PEG}$ & & & & & \\
\hline
\end{tabular}


Note S1. Comparison of critical nucleation radius and areal nuclei density in $1.0 \mathrm{M} \mathrm{ZnSO}_{4}$ and 1.0 $\mathrm{M} \mathrm{ZnSO}_{4}-1000$ ppm PEG electrolyte.

The critical nucleation radius $\left(r_{c r i t}\right)$ for forming a spherical nucleus obeys the following equation: $:^{1,2}$

$$
r_{c r i t}=\frac{2 \gamma_{S L} V_{m}}{F / \eta /}
$$

where $\gamma_{S L}$ is the surface energy of $\mathrm{Zn}$ /electrolyte interface, $V_{m}$ is the molar volume of $\mathrm{Zn}, F$ is Faraday's constant, and $\eta$ is the nucleation overpotential. In this system, there exist two variables, which are the surface energy $\gamma_{S L}$ and overpotential $\eta$, respectively. The surface energy $\gamma_{S L}$ can be derived from the Young Equation as following: ${ }^{3}$

$$
\gamma_{S V}=\gamma_{S L}+\gamma_{L V} \cos \theta
$$

where $\gamma_{S V}, \gamma_{S L}, \gamma_{L V}$ corresponds to interfacial tensions of solid to vapor, solid to liquid and liquid to vapor, respectively. $\theta$ is the contact angle of a liquid on a solid surface. Since the interfacial tension of $\mathrm{Zn}$ to vapor $\gamma_{S V}$ is a constant, $\left(\gamma_{L V} \cos \theta\right)_{b a r e}<\left(\gamma_{L V} \cos \theta\right)_{P E G}$, thus $\left(\gamma_{S L}\right)_{\text {bare }}>\left(\gamma_{S L}\right)_{P E G}$. Due to the adsorption of PEG on $\mathrm{Zn}$, the overpotential in the PEG-added electrolyte is larger than in the bare electrolyte. Therefore, the critical nucleation radius $r_{\text {crit }}$ in the $\mathrm{ZnSO}_{4}-\mathrm{PEG}$ electrolyte is smaller than in the bare electrolyte, which is favorable for forming fine grains and uniform deposition.

For sphercial deposition with the same areal capacity, the cirtical nucleation volume is $V_{\text {crit }}=$ $\frac{4 \pi}{3} r_{\text {crit }}^{3}$, and thus the PEG-added electrolyte offers smaller critical nucleation volume and larger areal nuclei density, which is consistent with the previous report ${ }^{1}$. 


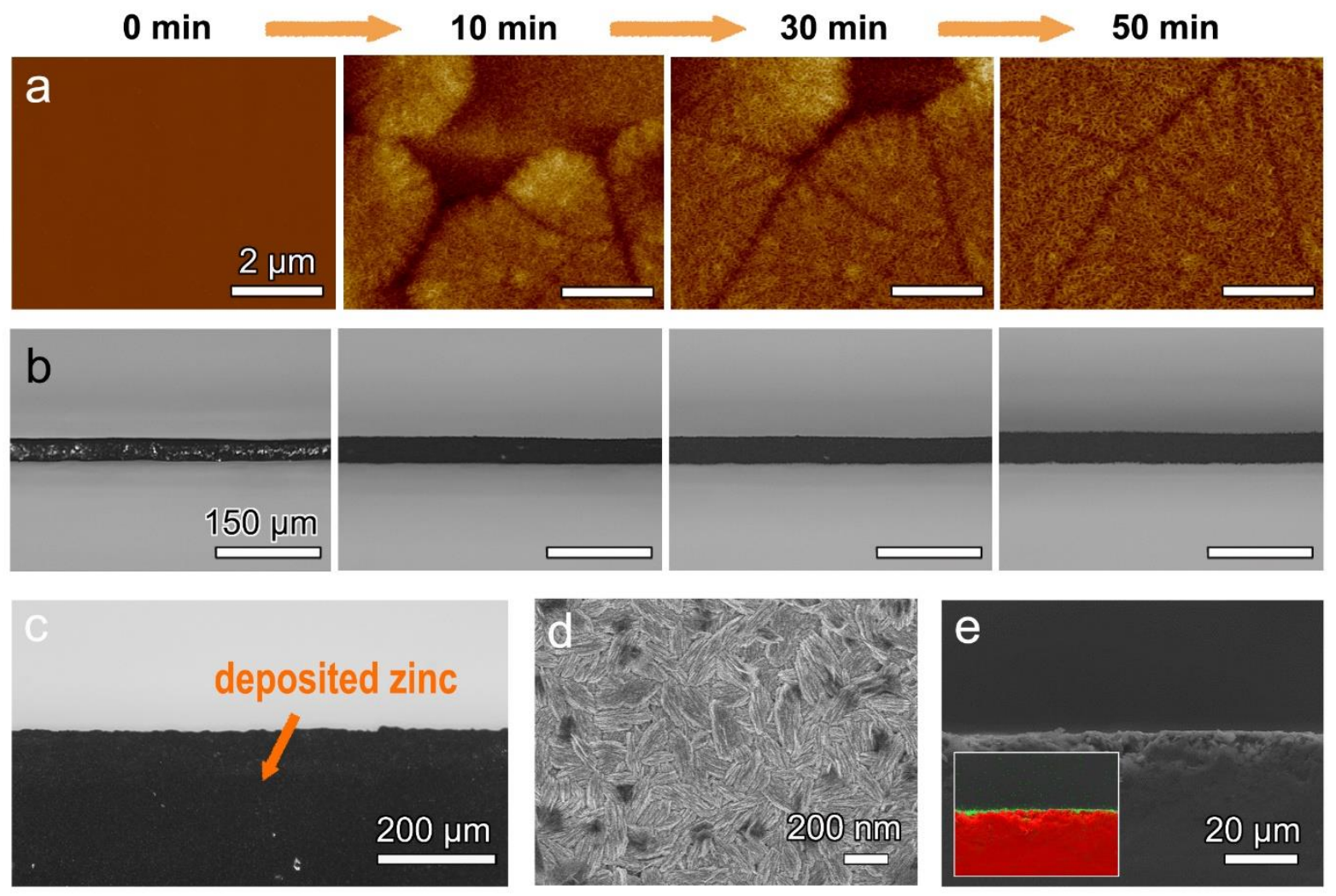

Figure S11. (a) In situ AFM images and (b) optical cross-section observations of the $\mathrm{Zn}$ deposition as a function of deposition time in $1.0 \mathrm{M} \mathrm{ZnSO}_{4}$ electrolyte. The data scale in AFM image is $300 \mathrm{~nm}$. (c) Plane-view optical picture of (b). (d) Top view and (e) cross section SEM images of deposited $\mathrm{Zn}$ in $1.0 \mathrm{M} \mathrm{ZnSO}_{4}$ electrolyte, the inset is elemental mapping. 

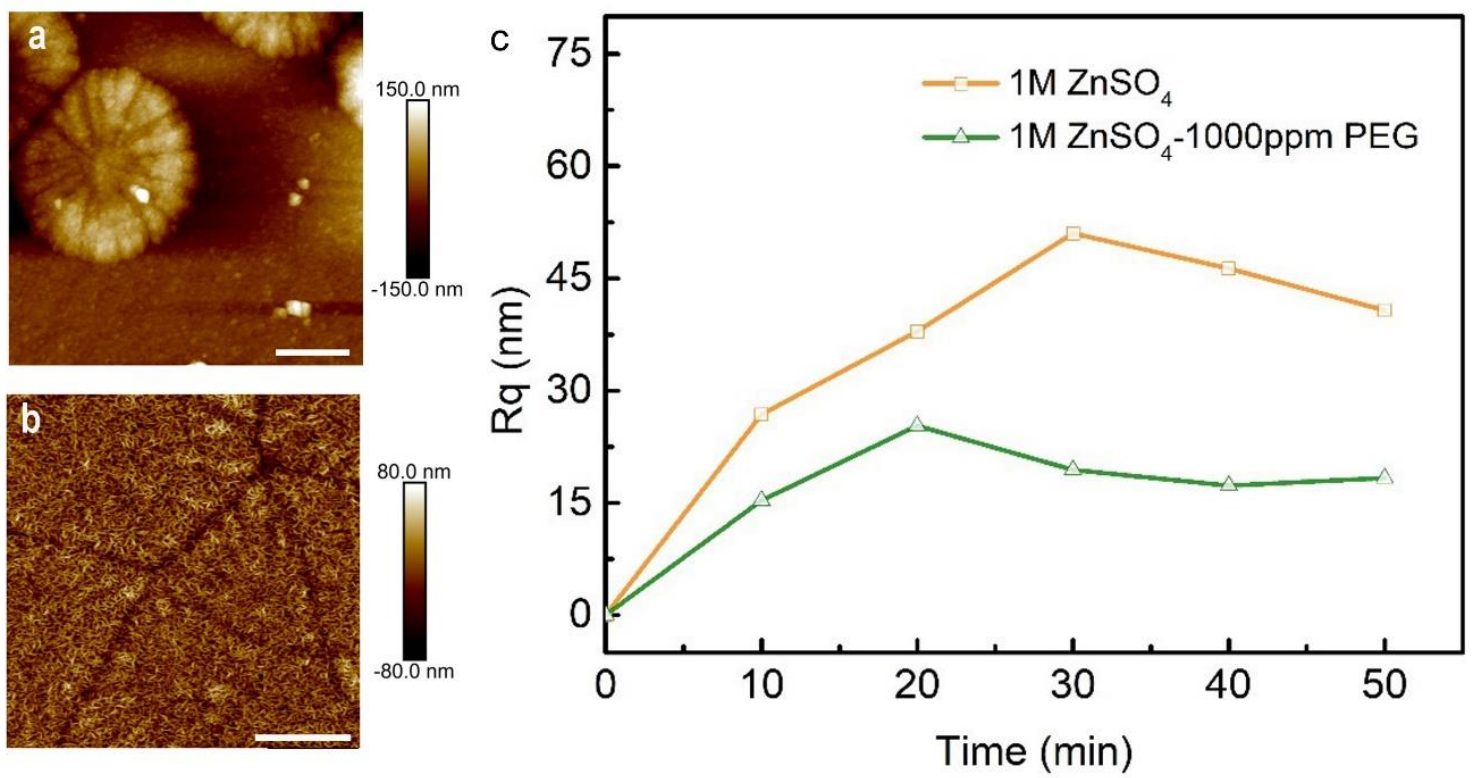

Figure S12. Comparison of deposited morphology in (a) $1.0 \mathrm{M} \mathrm{ZnSO}_{4}$ and (b) $1.0 \mathrm{M} \mathrm{ZnSO}_{4}$ 1000 ppm PEG electrolyte. The scale bar is $2 \mu \mathrm{m}$. (c) Roughness of in situ AFM images of deposited $\mathrm{Zn}$ in the two electrolytes.

In order to indicate the change of surface morphology quantitatively, the roughness (Rq) analysis is carried out. $\mathrm{Rq}$ can be expressed as the following equation $\mathrm{S} 3 \mathrm{i}^{4}$

$$
R_{q}=\sqrt{\frac{\sum_{i=1}^{n}\left(Z_{i}-\bar{Z}\right)^{2}}{N}}
$$

where $Z_{i}$ is the height value of the AFM topography image, $\bar{Z}$ is the mean value of the height data, and $N$ is the number of points within the image. 

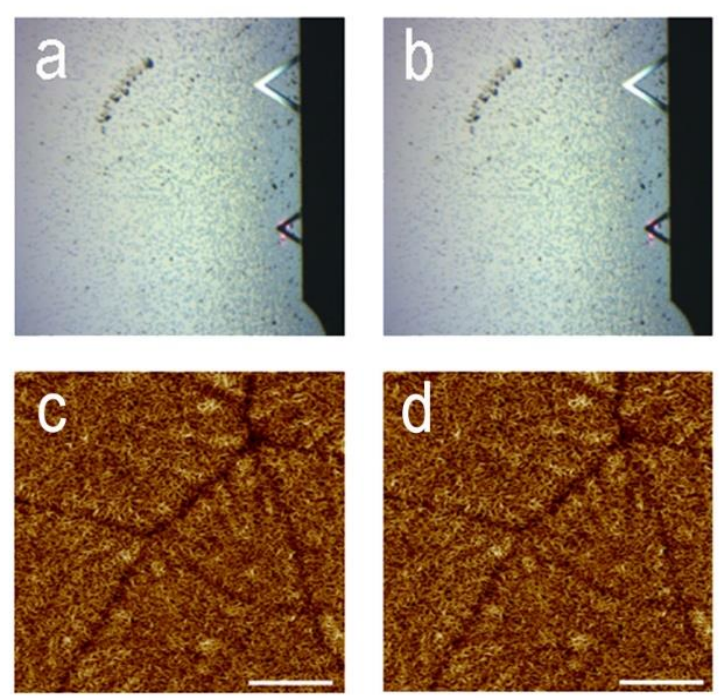

$-80 \mathrm{~nm}$

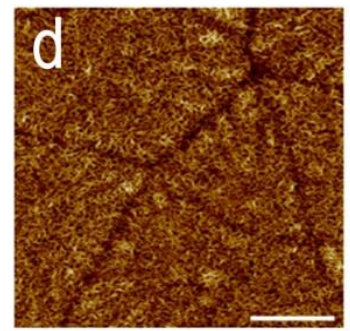

$80 \mathrm{~nm}$
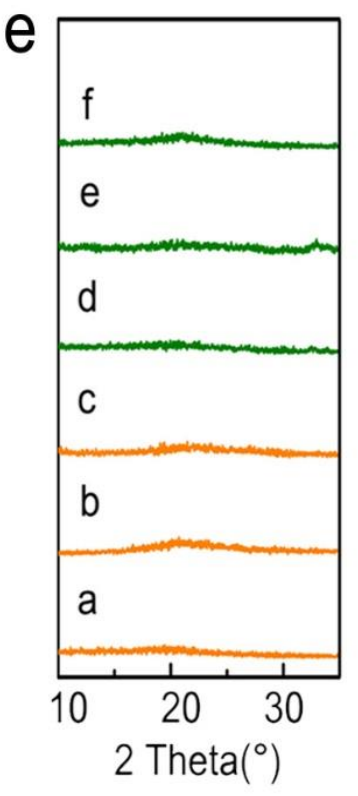

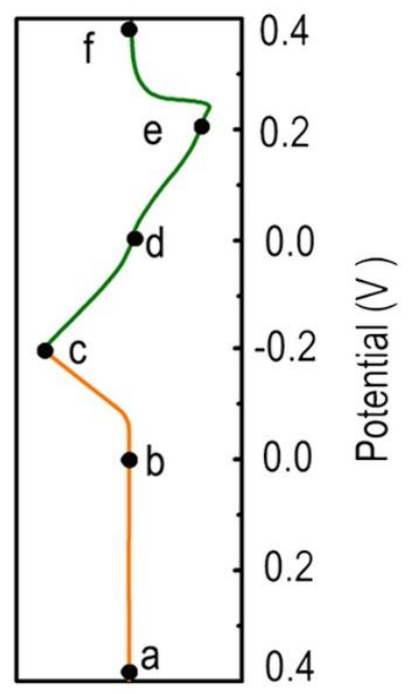

Current (a.u.)

Figure S13. (a,b) Optical images and (c,d) AFM images of planar electrode under quasi-zero electrochemical field in 1.0 $\mathrm{M} \mathrm{ZnSO}_{4}-1000$ ppm PEG electrolyte. The scale bar of the AFM image is $2 \mu \mathrm{m}$. (e) Ex situ XRD patterns and corresponding CV curve at a scan rate of $1 \mathrm{mV} \mathrm{s}^{-1}$, the points a-f mark the states where data are collected for XRD analysis. After settling the planar electrode in quasi-zero electrochemical field for $10 \mathrm{~min}$, the surface of electrode doesn't change in the electrolyte with PEG additive, which means the existence of PEG additive can restrain the self-corrosion of $\mathrm{Zn}$. 

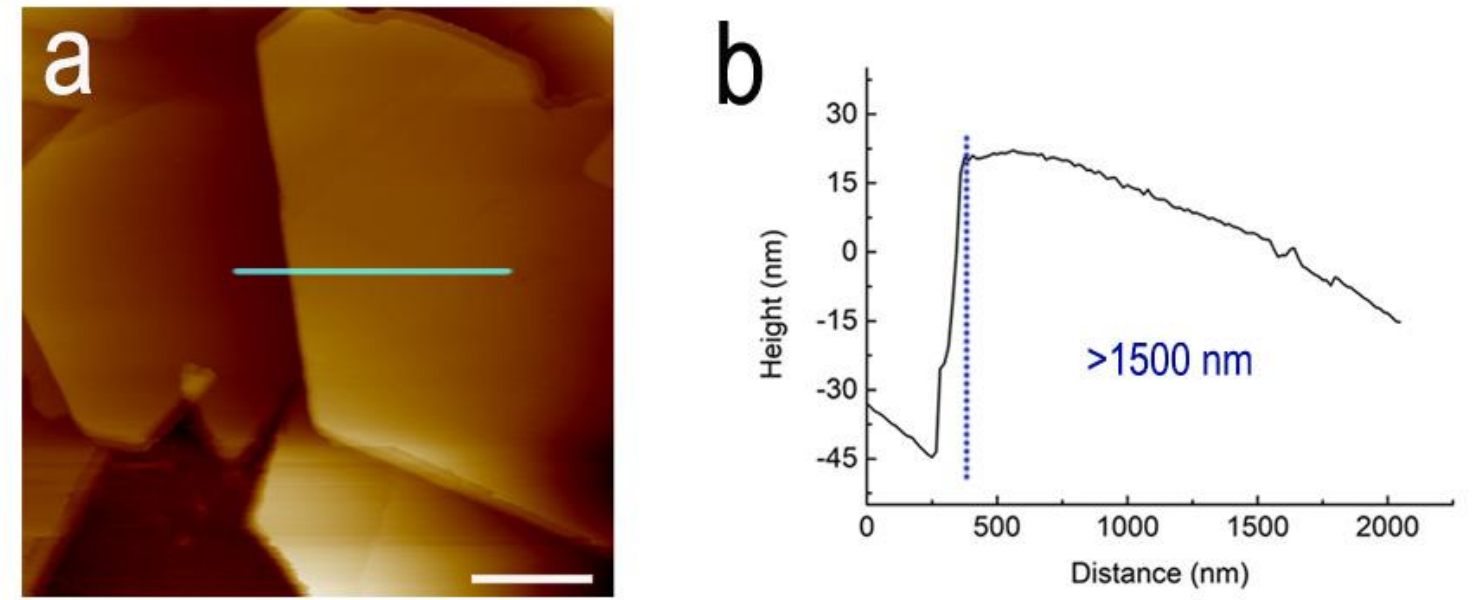

$-180.6 \mathrm{~nm}$

$146.0 \mathrm{~nm}$

Figure S14. (a) Morphology and (b) corresponding height of absorbed PEG layer. The data scale is $600 \mathrm{~nm}$. 


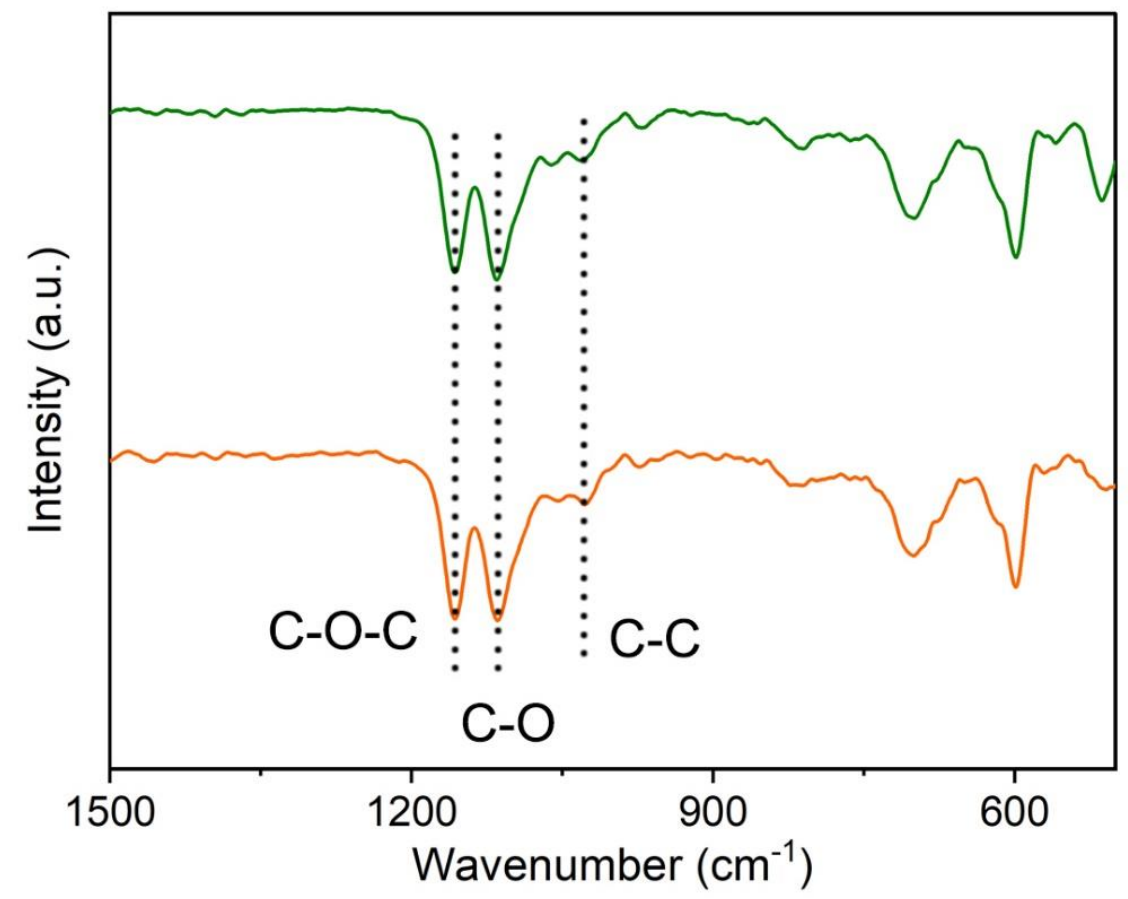

Figure S15. FTIR on stainless steel of $1^{\text {st }}$ cycle (orange curve) and $100^{\text {th }}$ cycle (green curve). Some characteristic stretching vibrations of PEG are observed, such as the symmetric C-O-C stretching at $\sim 1160 \mathrm{~cm}^{-1}$, the $\mathrm{C}-\mathrm{O}$ stretching at $\sim 1080 \mathrm{~cm}^{-1}$, and the $\mathrm{C}-\mathrm{C}$ stretching at $\sim 966 \mathrm{~cm}^{-1}$. The characteristic stretching vibrations of PEG are obvious after 100 cycle, indicating that PEG is still workable. 


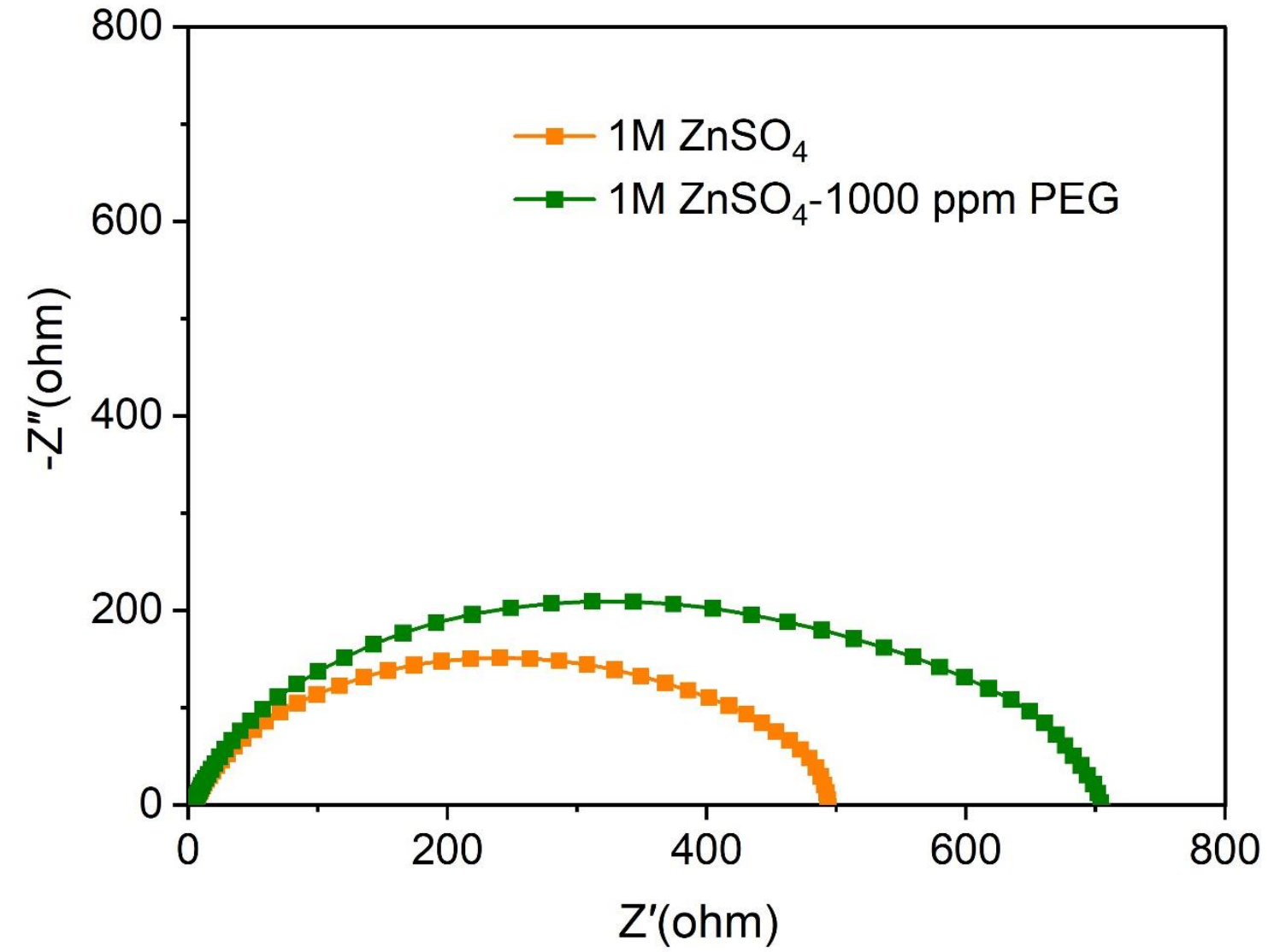

Figure S16. Electrochemical impedance spectroscopy measured in Zn//Zn symmetric cell. 

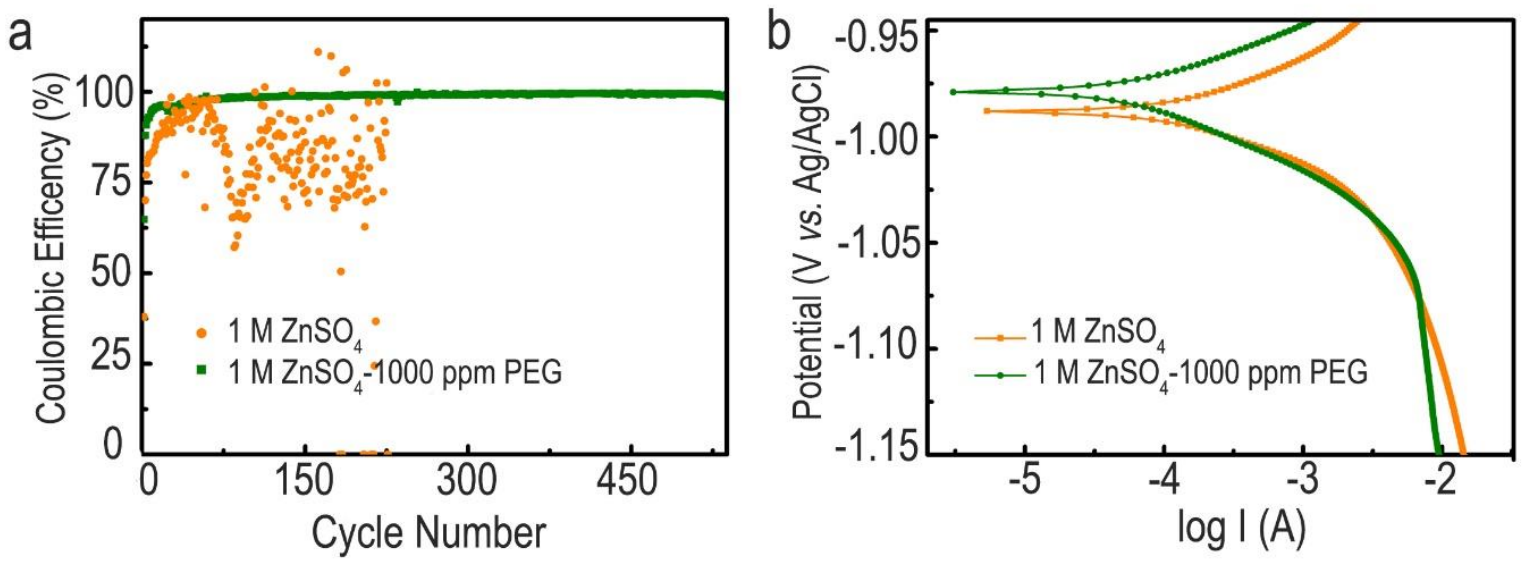

Figure S17. Comparison of electrochemical performance in $1.0 \mathrm{M} \mathrm{ZnSO}_{4}$ and $1.0 \mathrm{M} \mathrm{ZnSO}_{4}-$ 1000 ppm PEG electrolyte. (a) Coulombic efficiency and (b) Tafel plots.

The Coulombic efficiency in $1.0 \mathrm{M} \mathrm{ZnSO}_{4}$ is $86.9 \%$ at $10^{\text {th }}$ cycle and unstable after 73 cycles (corresponding to $135 \mathrm{~h}$ ). In contrast, the Coulombic efficiency can reach $95.1 \%$ at $10^{\text {th }}$ cycle and increase to $99.6 \%$ after 540 cycles (about $1070 \mathrm{~h}$ ) in electrolyte with PEG additive. The enhanced electrochemical stability is attributed to the dendrite-free surface and effective suppression of side-reactions. Figure S17b presents the Tafel plots in both the bare and PEGadded electrolytes, from which the corrosion potential $\left(E_{c o r r}\right)$ and corrosion current density $\left(I_{c o r r}\right)$ can be obtained. The estimated corrosion current density in the bare and $\mathrm{ZnSO}_{4}-\mathrm{PEG}$ electrolyte is 0.7943 and $0.3162 \mathrm{~A} \mathrm{~m}^{-2}$, respectively. Higher corrosion resistance is realized with corrosion inhibition efficiency $\left(\eta_{p}\right)$ of $60.2 \%$ in the electrolyte with PEG, which is calculated based on the equation $\mathrm{S} 4:^{6}$

$$
\eta_{p}=\frac{I_{c o r r}-I_{c o r r}^{\prime}}{I_{c o r r}} \times 100 \%
$$

where $I_{\text {corr }}$ is the corrosion current density in the bare electrolyte, and $I_{\text {corr }}^{\prime}$ is the corrosion current density in the electrolyte with PEG inhibitor. 
a

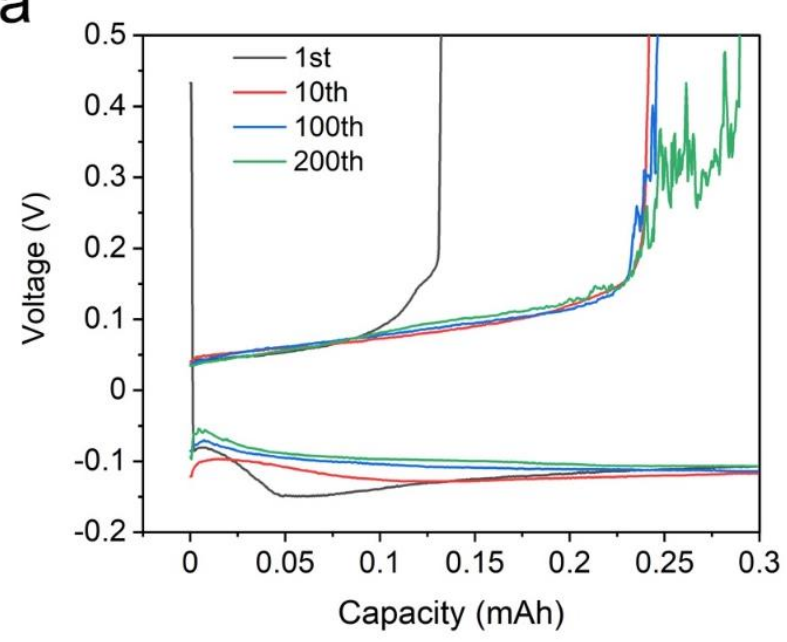

b

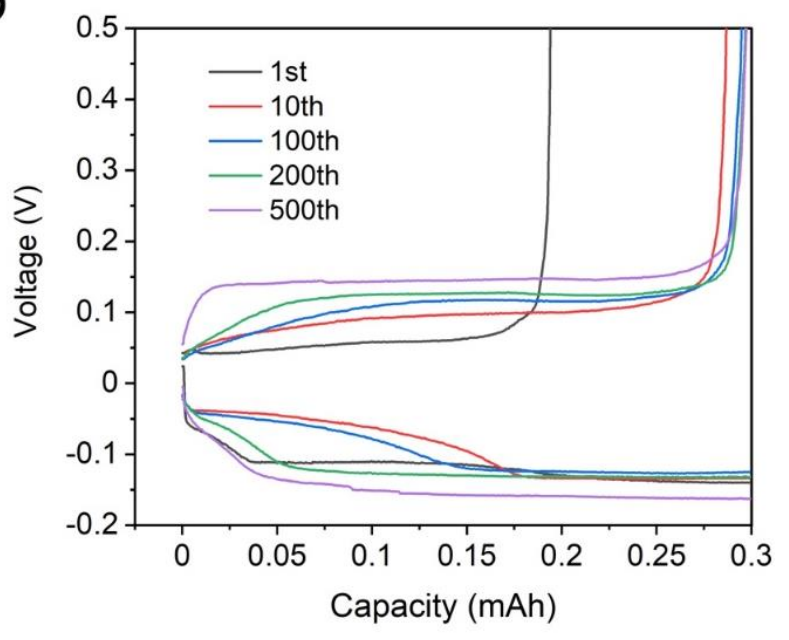

Figure S18. Cycling curves of Coulombic efficiency in (a) $1.0 \mathrm{M} \mathrm{ZnSO}_{4}$ and (b) $1.0 \mathrm{M} \mathrm{ZnSO}_{4-}$ 1000 ppm PEG electrolyte. 
Table S2. Summary of recently reported strategies for the optimization of Zn-electrolyte interface.

\begin{tabular}{|c|c|c|c|c|c|}
\hline Anode Materials & Electrolyte & Current Density & Areal Capacity & Lifespan & Ref. \\
\hline $\begin{array}{l}\mathrm{Zn} \text { foil coated with ultrathin } \\
\mathrm{TiO}_{2}\end{array}$ & $3 \mathrm{M} \mathrm{Zn}\left(\mathrm{CF}_{3} \mathrm{SO}_{3}\right)_{2}$ & $1 \mathrm{~mA} \mathrm{~cm}^{-2}$ & $1 \mathrm{mAh} \mathrm{cm}^{-2}$ & $150 \mathrm{~h}$ & 7 \\
\hline $\begin{array}{l}\mathrm{Zn} \text { foil coated with nano } \\
\mathrm{CaCO}_{3}\end{array}$ & $3 \mathrm{M} \mathrm{ZnSO}_{4}+0.1 \mathrm{M} \mathrm{MnSO}_{4}$ & $0.25 \mathrm{~mA} \mathrm{~cm}^{-2}$ & $0.05 \mathrm{mAh} \mathrm{cm} \mathrm{cm}^{-2}$ & $836 \mathrm{~h}$ & 8 \\
\hline $\mathrm{Zn}$ foil coated with rGO & $1 \mathrm{M} \mathrm{ZnSO}_{4}$ & $1 \mathrm{~mA} \mathrm{~cm}^{-2}$ & $2 \mathrm{mAh} \mathrm{cm}^{-2}$ & $200 \mathrm{~h}$ & 9 \\
\hline $\mathrm{Zn} /$ carbon nanotubes & $2 \mathrm{M} \mathrm{ZnSO}_{4}$ & $2 \mathrm{~mA} \mathrm{~cm}^{-2}$ & $2 \mathrm{mAh} \mathrm{cm}^{-2}$ & $200 \mathrm{~h}$ & 10 \\
\hline Zn foil coated with polyamide & $2 \mathrm{M} \mathrm{ZnSO}_{4}$ & $0.5 \mathrm{~mA} \mathrm{~cm}^{-2}$ & $0.25 \mathrm{mAh} \mathrm{cm}^{-2}$ & $8000 \mathrm{~h}$ & 11 \\
\hline $\mathrm{Zn}$ foil & $3 \mathrm{M} \mathrm{Zn}\left(\mathrm{CF}_{3} \mathrm{SO}_{3}\right)_{2}+$ diethylether & $0.2 \mathrm{~mA} \mathrm{~cm}^{-2}$ & $0.2 \mathrm{mAh} \mathrm{cm}^{-2}$ & $250 \mathrm{~h}$ & 12 \\
\hline Zn plated copper mesh & $\begin{array}{c}1 \mathrm{M} \mathrm{ZnSO}_{4}+0.5 \mathrm{M} \mathrm{Na}_{2} \mathrm{SO}_{4}+1 \mathrm{~g} \mathrm{~L}^{-1} \\
\text { PAM }\end{array}$ & $0.2 \mathrm{~mA} \mathrm{~cm}^{-2}$ & $1 \mathrm{mAh} \mathrm{cm}^{-2}$ & $350 \mathrm{~h}$ & 13 \\
\hline Zn powder & $20 \mathrm{M} \mathrm{LiTFSI}+1 \mathrm{M} \mathrm{Zn(TFSI})_{2}$ & $0.2 \mathrm{~mA} \mathrm{~cm}^{-2}$ & $0.035 \mathrm{mAh} \mathrm{cm}^{-2}$ & $170 \mathrm{~h}$ & 14 \\
\hline $\mathrm{C}$ coated $\mathrm{Zn}$ & $\mathrm{M} \mathrm{NaClO}_{4}+0.4 \mathrm{M} \mathrm{Zn}\left(\mathrm{CF}_{3} \mathrm{SO}_{3}\right)_{2}$ & $1 \mathrm{~mA} \mathrm{~cm}^{-2}$ & $1 \mathrm{mAh} \mathrm{cm}^{-2}$ & $100 \mathrm{~h}$ & 15 \\
\hline $\mathrm{Zn}$ foil & $1 \mathrm{M} \mathrm{ZnSO}_{4}+1000$ ppm PEG & $1 \mathrm{~mA} \mathrm{~cm}^{-2}$ & $1 \mathrm{mAh} \mathrm{cm} \mathrm{c}^{-2}$ & $570 \mathrm{~h}$ & $\begin{array}{l}\text { This } \\
\text { work }\end{array}$ \\
\hline
\end{tabular}



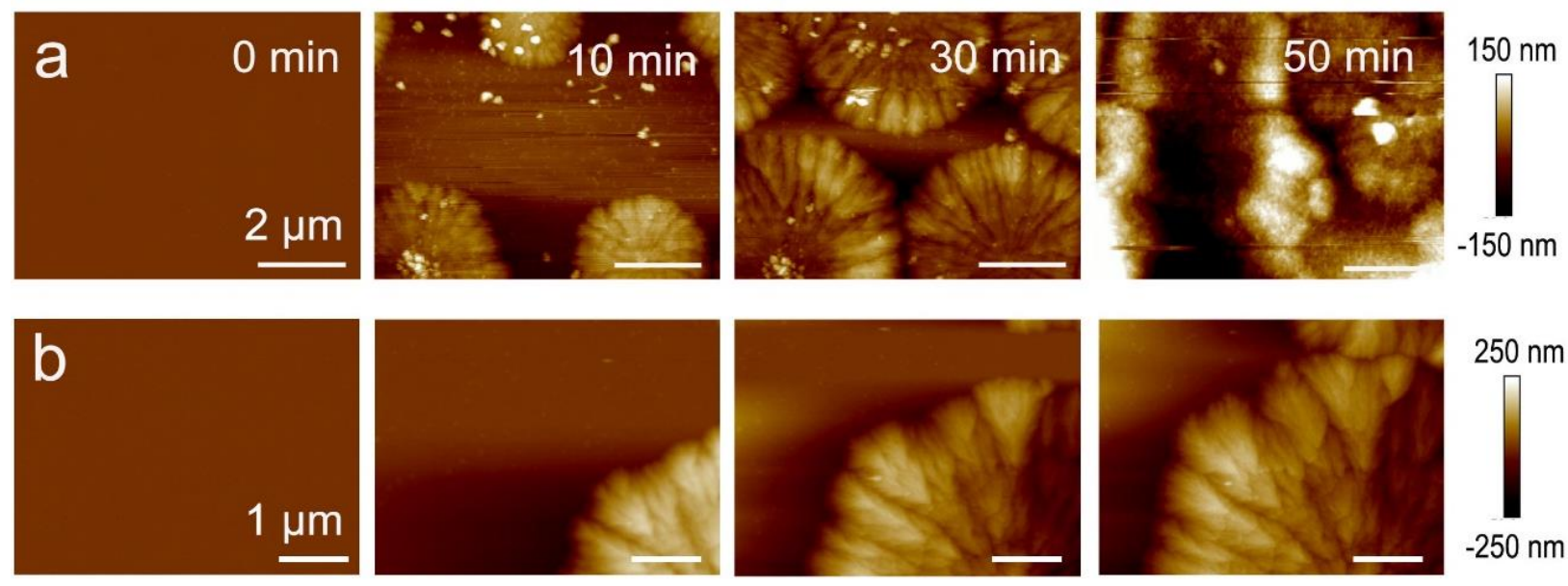

Figure S19. In situ AFM topography images of timeline-based deposition process in (a) $3.0 \mathrm{M}$ $\mathrm{ZnSO}_{4}$ and (b) $1.0 \mathrm{M} \mathrm{Zn}\left(\mathrm{CF}_{3} \mathrm{SO}_{3}\right)_{2}$ electrolyte. The current density is $0.04 \mathrm{~mA} \mathrm{~cm}{ }^{-2}$.

\section{Supplementary references:}

(1) Pei, A.; Zheng, G.; Shi, F.; Li, Y.; Cui, Y. Nanoscale Nucleation and Growth of Electrodeposited Lithium Metal. Nano Lett. 2017, 17, 1132-1139.

(2) Plieth, W. Electrochemistry for Materials Science. Elsevier, Amsterdam, 2008.

(3) Nosonovsky, M.; Ramachandran, R. Geometric Interpretation of Surface Tension Equilibrium in Superhydrophobic Systems. Entropy 2015, 17, 4684-4700.

(4) Han, M.; Zhu, C.; Ma, T.; Pan, Z.; Tao, Z.; Chen, J. In Situ Atomic Force Microscopy Study of Nano-micro Sodium Deposition in Ester-based Electrolytes. Chem. Commun. 2018, 54, 2381-2384.

(5) Mitha, A.; Yazdi, A. Z.; Ahmed, M.; Chen, P. Surface Adsorption of Polyethylene Glycol to Suppress Dendrite Formation on Zinc Anodes in Rechargeable Aqueous Batteries. Chemelectrochem 2018, 5, 2409-2418.

(6) Liang, M.; Zhou, H.; Huang, Q.; Hu, S.; Li, W. Synergistic Effect of Polyethylene Glycol 600 and Polysorbate 20 on Corrosion Inhibition of Zinc Anode in Alkaline Batteries. J. Appl. Electrochem. 2011, 41, 991-997.

(7) Zhao, K.; Wang, C.; Yu, Y.; Yan, M.; Wei, Q.; He, P.; Dong, Y.; Zhang, Z.; Wang, X.; Mai, L. Ultrathin Surface Coating Enables Stabilized Zinc Metal Anode. Adv. Mater. Interfaces 2018, 5, 1800848.

(8) Kang, L.; Cui, M.; Jiang, F.; Gao, Y.; Luo, H.; Liu, J.; Liang, W.; Zhi, C. Nanoporous $\mathrm{CaCO}_{3}$ Coatings Enabled Uniform Zn Stripping/plating for Long-life Zinc Rechargeable Aqueous Batteries. Adv. Energy Mater. 2018, 8, 1801090. 
(9) Shen, C.; Li, X.; Li, N.; Xie, K.; Wang, J.-g.; Liu, X.; Wei, B. Graphene-boosted, Highperformance Aqueous Zn-ion Battery. ACS Appli. Mater. Interfaces 2018, 10, 25446-25453.

(10) Zeng, Y.; Zhang, X.; Qin, R.; Liu, X.; Fang, P.; Zheng, D.; Tong, Y.; Lu, X. Dendritefree Zinc Deposition Induced by Multifunctional CNT Frameworks for Stable Flexible Zn-ion Batteries. Adv. Mater. 2019, 31, 1903675.

(11) Zhao, Z.; Zhao, J.; Hu, Z.; Li, J.; Li, J.; Zhang, Y.; Wang, C.; Cui, G. Long-life and Deeply Rechargeable Aqueous Zn Anodes Enabled by a Multifunctional Brightener-inspired Interphase. Energy Environ. Science 2019, 12, 1938-1949.

(12) Xu, W.; Zhao, K.; Huo, W.; Wang, Y.; Yao, G.; Gu, X.; Cheng, H.; Mai, L.; Hu, C.; Wang, X. Diethyl Ether as Self-healing Electrolyte Additive Enabled Long-life Rechargeable Aqueous Zinc Ion Batteries. Nano Energy 2019, 62, 275-281.

(13) Zhang, Q.; Luan, J.; Fu, L.; Wu, S.; Tang, Y.; Ji, X.; Wang, H. The Three-dimensional Dendrite-free Zinc Anode on a Copper Mesh with a Zinc-oriented Polyacrylamide Electrolyte Additive. Angew Chem. Int. Ed. Engl. 2019, 58, 15841-15847.

(14) Wang, F.; Borodin, O.; Gao, T.; Fan, X.; Sun, W.; Han, F.; Faraone, A.; Dura, J. A.; Xu, K.; Wang, C. Highly Reversible Zinc Metal Anode for Aqueous Batteries. Nat. Mater. 2019, 17, 543-549.

(15) Li, W.; Wang, K.; Zhou, M.; Zhan, H.; Cheng, S.; Jiang, K. Advanced Low-cost, Highvoltage, Long-life Aqueous Hybrid Sodium/zinc Batteries Enabled by a Dendrite-free Zinc Anode and Concentrated Electrolyte. ACS Appl. Mater. Interfaces 2018, 10, 22059-22066. 